\title{
Los derechos constitucionales y el ejercicio del poder por el general Salaverry en una tradición de Palma
}

\author{
Iván Rodríguez Chávez \\ Universidad Ricardo Palma \\ irodriguez@urp.edu.pe \\ Lima-Perú
}

\section{Resumen}

A propósito del análisis jurídico de la tradición «Al pie de la letra», se revela un ambiente político y jurídico en la primera década de la vida republicana en la que el presidente de la República es un militar que ha llegado al gobierno por la acción de la fuerza y la violencia armada y en la que los derechos constitucionales de los habitantes no eran respetados, configurándose una situación de vigencia teórica de la Constitución Política de 1834 y la inaplicación de los derechos constitucionales, afectando la vida social de las personas.

Palabras clave: Militar, disciplina, obediencia, órdenes, constitución, derechos constitucionales.

\section{Abstract}

When conducting a legal analysis of the Tradition Al pie de la letra, a political and legal environment is revealed in the first decade of the Republican life, where the president of the Republic is a military member that seizes control of the government through armed violence, and it also revealed a decade where constitutional rights were not respected. It is in this context that a situation of theoretical validity for the Political Constitution of 1834 arises, as well as the non-application of constitutional rights, affecting people's social lives.

Keywords: Military, discipline, obedience, orders, constitution, constitutional rights 


\section{Iván Rodríguez Chávez (Perú)}

Doctor y magíster en Educación, profesor de castellano y literatura y abogado por la Universidad Mayor de San Marcos. Docente universitario en literatura peruana, introducción al Derecho y legislación universitaria. Ex Presidente de la Asamblea Nacional de Rectores. Ex Presidente del Consejo Andino (CONSUAN) y del Consejo Universitario Iberoamericano (CUIB). Ex miembro del Consejo Nacional de Educación, Presidente de la Asociación de Universidades del Perú. Rector de la Universidad Ricardo Palma. Recibió la más alta condecoración «Palmas Magistrales en el grado de Amauta» otorgada por el Ministerio de Educación del Perú. Participa en congresos y certámenes literarios y universitarios. Autor de libros, artículos y ponencias sobre literatura peruana, educación y legislación universitaria, que se publican en revistas universitarias y prensa escrita. 


\section{Introducción}

Teniendo como objetivo promover el aprendizaje del Derecho empleando la Literatura, en esta oportunidad se analizará «Al pie de la letra», una tradición escrita por Ricardo Palma que, metodológicamente, se convierte en un caso en el que se identifica el ambiente político en la primera década de vida independiente del Perú que servía de contexto social y jurídico para el uso del poder por los más altos gobernantes y la no vigencia de los derechos constitucionales de las personas.

Este artículo se desarrollará aplicando el método de análisis, interpretación y comentario del texto centrándose en la presentación de la conducta jurídica de los personajes y las normas a las cuales deben sujetarse sus actos que, literariamente captados y transmitidos por la pluma de Palma, pintan un panorama de vigencia teórica de la Constitución y una realidad escenario de transgresión de los derechos consagrados por esta.

\section{Análisis literario del texto}

\section{El autor}

Ricardo Palma (1833-1919) nació y murió en Lima. Durante su larga vida, dedicó cerca de sesenta años a la escritura, habiendo llegado a producir un aproximado de 450 tradiciones, además de poesías, artículos periodísticos, biografías, ensayos históricos y de crítica literaria; diccionarios de peruanismos y algo de teatro. Palma llenó una época en la historia de la literatura peruana, habiendo sido uno de los pocos escritores que influyó en otros creando un estilo que llegó a difundirse en toda Hispanoamérica.

El conjunto de sus tradiciones recorre temáticamente las diferentes etapas de la historia del Perú: un poco sobre los 
Incas, otro tanto para la Conquista; mucho para el Virreinato, y, un tanto de ellas, dedicado a la Emancipación y la República. En el grupo de esta última etapa se ubica «Al pie de la letra» (1953, pp. 1068-1070).

\section{El texto}

No estuvo en la intención de Palma construir un texto jurídico, porque la tradición es un texto literario; por lo tanto, su intención fue estética; es decir, Palma se propuso componer una narración corta sobre una anécdota real protagonizada por el personaje principal que le sirve de base para combinar esa verdad con su fantasía de escritor romántico, no exenta de algo de humor. Ahora, independientemente de la intención, Palma conoció el ambiente político de las primeras décadas de la Independencia y la no vigencia de los derechos constitucionales y los incorporó como contenido del texto.

\subsection{El argumento}

En «Al pie de la letra», Palma narra las relaciones de disciplina y obediencia militar establecidas entre el general Felipe Santiago Salaverry, el jefe que emitía las órdenes, y el capitán Paiva, el subalterno que las cumplía atípicamente.

A estos vínculos estrictamente castrenses se adicionaban el trato amistoso y la confianza plena que Salaverry tenía depositada en Paiva.

En la primera historia, el general Salaverry llama al capitán Paiva y le ordena buscar a un «Fulano» para apresarlo, indicándole que si no lo encontraba en el sitio indicado, fuera por él a su casa, autorizándole el allanamiento; es decir, el ingreso con la fuerza armada al interior de su domicilio con el objeto de 
aprehenderlo. Al rato, regresó el capitán Paiva para dar cuenta del cumplimiento de la orden a su general, informándole que al no haber encontrado a la persona sindicada había allanado su casa; vale decir, había demolido la casa, dejándola sin ninguna «pared en pie».

En la segunda historia, Palma cuenta que nuevamente el general Salaverry llama al capitán Paiva para comisionarle el castigo a su asistente, el soldado apodado Cuculí, de fusilarlo, pero solo con la intención de asustarlo.

Paiva tampoco entendió que esta orden era de apariencia, ejecutando de inmediato el fusilamiento, sin dejar al general Salaverry la oportunidad de dictar la contraorden antes de la ejecución.

Hay en la tercera historia una diferencia respecto a la orden. En buena cuenta esta no se ha producido. Salaverry formalmente no ha dictado ninguna. Solo le dijo a Paiva: «Déjame en paz. Haz lo que quieras. Anda y hazte matar» (p. 1070), expresión coloquial que fue tomada por Paiva como una orden. Esta equívoca interpretación fue el origen de su propia muerte. Deteniéndonos en los detalles, la acción narrada en esta tercera historia registra la aparición de un grupo armado contrario a Salaverry. Avisado este, en el lugar del campo de batalla, considera que su ejército no corría peligro; razón por la que no dispone ningún ataque. Ante esta determinación del general Salaverry, el capitán Paiva tiene la iniciativa de atacar. Con este objeto pide permiso al general, quien no accede. La negativa de su superior no disuade al capitán, quien insistirá mucho hasta que el general mortificado le dijo: «Déjame en paz. Haz lo que quieras. Anda y hazte matar», no constituyendo esta expresión una orden. Sin embargo, el capitán Paiva escogió un grupo de soldados con los cuales atacó al enemigo con tan gran valor e ímpetu que fue alcanzado por dos balas en el pecho y una en el abdomen. No obstante estas 
heridas cumplió su promesa de llegar ante el general todavía montado en su caballo con un soldado enemigo muerto por él en el combate. Con tal suceso, Palma redondea el perfil del militar de fuerza bruta y escasez de inteligencia, con un sentido ciego del deber y lealtad; capaz de sacrificar su propia vida, tomando literalmente como una orden la frase «Hazte matar».

Si bien la tradición «Al pie de la letra» está conformada por tres historias con una acción distinta cada una de ellas, la unidad textual viene determinada por la actuación de los dos personajes centrales y la presencia permanente de la disciplina militar sin importar si el resultado de la ejecución de la orden está conforme a lo mandado o no.

\subsection{La estructura}

Consta de cuatro partes. La primera hace de introducción constituida por el retrato del personaje central, el capitán Paiva. Es presentado en su aspecto físico y moral dando referencias sobre su fama y su carrera militar marcada por sus cualidades de disciplina, cumplimiento, lealtad y conformismo con su jerarquía sin enfrentar ningún trastorno por su falta de ascenso. A la vez, en este retrato asoman las cualidades que no lo hacen apto para escalar a jerarquías superiores, como su incultura, su poca inteligencia y su actuación ruda distinta a la interpretación discrecional de las órdenes de sus superiores.

Inicia la segunda parte la presentación del general Felipe Santiago Salaverry «elevado (...) al mando de la República...» después de haberse autoproclamado «jefe supremo de la nación peruana» (p. 1069)

Palma, con esta muy corta presentación, ha dado ingreso a Salaverry, para asociar a Paiva, en las tres historias que conforman el texto. 
Según el plan y el desarrollo argumental del texto, su unidad proviene de la actuación de Paiva, que para ser retratado en los hechos requiere de la presencia de Salaverry en su papel de emisor de órdenes y Paiva en su rol de ejecutante de ellas, pero de una manera distinta a la intención con la que fueron impartidas. Consecuentemente, la unidad formal y de fondo no obstante la variedad de historias - se logra por los personajes y la temática de la disciplina militar que subyace en todas las acciones.

Por otro lado, las acciones transcurren dentro del marco temporal de 1835; año en que Salaverry se autoproclamó Jefe Supremo y como tal asumió la Presidencia de la República. Respecto al eje espacial, en la introducción, la primera y segunda historia, el autor no menciona expresamente ninguna ciudad como escenario de los hechos, pudiéndose inferir que pudiera tratarse de Lima por ser la sede del gobierno nacional. En la tercera historia, Palma sí consignó el lugar del enfrentamiento de los ejércitos: Chacllapampa, en ese entonces un paraje ubicado dentro de la circunscripción geográfica de Arequipa.

\subsection{Los personajes}

La tradición en estudio tiene dos personajes centrales que en conjunto proyectan la imagen del militar en las primeras décadas de la Independencia e inicios de la República, que le dan unidad al texto.

Sobre el capitán Paiva no hay más información histórica fuera del retrato que ofrece Palma. En la introducción está la síntesis de su vida: nacido en el Cusco, consagrado a la carrera militar no obstante que no asciende más, permaneciendo muchos años como capitán, sin perspectivas de subir a las jerarquías superiores. A pesar de esta situación, Paiva sigue firme en 
sus cualidades militares, desempeñando sus funciones con disciplina, buena voluntad, entrega y lealtad a su superior. La gran limitación para su carrera es su poca inteligencia o, como dice Palma, «la pobreza de su meollo». Más adelante, el propio autor se pregunta y se responde «iPor qué no ascendía Paiva? Por bruto y porque de serlo se había conquistado reputación piramidal» (p. 1069).

Esta peculiaridad del personaje probablemente haya influido en Palma para su presentación sin nombre de pila o prenombre, como queriendo decir que por su falta de méritos en escalar jerarquías era suficiente consignar solo el apellido; recurso narrativo que sitúa al capitán de las tres historias como medio identificado o medio anónimo, o como algo real y otro tanto de fantasía, conforme a la fórmula de la composición literaria de la tradición. Asimismo, las caracterizaciones de ambos personajes militares están diseñadas y tienen participación complementaria en el texto, encaminados a construir una sola imagen, aportando cada uno una modalidad de ser militar. Paralelamente a este tratamiento, a Paiva, Palma deja sentir el tono de respeto con el que dibuja el perfil profesional y humano que esboza sobre él.

El otro personaje central, el general Salaverry, es la figura cuyos contornos los delinea con respeto y admiración por su firmeza y energía en sus determinaciones. En ninguna parte del texto aparece inseguro o vacilante, aún en sus órdenes más duras como la del fusilamiento.

Desde las primeras líneas de su ingreso al escenario narrativo, Palma lo anuncia con el título de «jefe supremo de la nación peruana»; fórmula que con variantes se repite en adelante como «jefe supremo», combinando con referencias afectivas en algunos pasajes en las que el narrador deja de lado las de jefe supremo y general para aludirlo con sus nombres: ya «don 
Felipe Santiago» o ya «don Felipe» cuando se van configurando escenas de corte amical antes que políticas o protocolares.

Además de respeto, la forma cómo alude Palma a él insinúa también simpatía que quedaría corroborada con otras tres tradiciones: «La Salaverrina» y «Una genialidad», en la que se adueña del texto como personaje central; y «La proeza de Benites», cuyo estrellato comparte justamente con Benites, otro capitán del ejército de Salaverry. Respecto al nombre, Palma, en esta tradición, trata a Salaverry con su apellido, pero hay pasajes del texto en los que la referencia la hace mediante sus nombres de pila, ya señalados en el párrafo anterior.

Independientemente de la simpatía que Salaverry despierta en Palma, la personalidad y la vida de este general se presta para la inspiración literaria, con mayor razón si tenemos en cuenta que Palma era un escritor romántico, que siempre aprovechaba los ángulos especiales que ofrecían estos para construir un texto literario; mezclando un poco de verdad y otro poco de fantasía, como él mismo definió a su tradición.

Llamábase Felipe Santiago Salaverry, aunque en su partida bautismal aparecen los nombres de Felipe Mariano de la Cruz, correspondiéndole a su padre el de Felipe Santiago (Zanutelli, 1994). Nació en Lima, según este mismo documento, el 3 de mayo de 1806. Luego, ante la llegada de las fuerzas libertadoras de San Martín se enroló como voluntario en su ejército aún siendo adolescente. A partir de esa fecha va a participar en diferentes acciones de armas, siendo las más significativas Junín y Ayacucho. Establecida la República sigue en la carrera militar destacándose por su arrojo y su valor. Sobre la base de su participación en batallas desatadas por los caudillos militares consiguió rápidos ascensos. El general Luis José Orbegoso, presidente de la República, lo promovió en corto tiempo a la jerarquía de coronel y al rango de general de brigada. Como tal, 
develó un motín militar en el castillo del Real Felipe en el Callao y pronto se sublevó contra el presidente constitucional, general Luis José Orbegoso, aprovechando que se había ido a Arequipa a combatir a Santa Cruz, habiendo dejado el despacho de la Presidencia a Manuel Salazar y Baquíjano, el mismo que, fiel a Orbegoso, se retiró a Jauja. Este hecho ocurrió la noche del 22 de febrero de 1835, fecha en la que a la vez el general Salaverry se autoproclamó Jefe Supremo, ocupando de facto, por la fuerza de las armas, la Presidencia de la República.

En ese año de 1835, cuatro caudillos militares se disputaban la hegemonía del poder: «Orbegoso, que era el presidente legítimo, constitucional»; Salaverry, que encabezaba «un régimen de facto que controlaba gran parte del país», menos Arequipa; «Gamarra, que actuaba en el sur con bandera propia»; y «Santa Cruz, que intervenía a solicitud del presidente legal», es decir, de Orbegoso (Durand, 1998, p. 198, t. V). Encontrándose el país en los prolegómenos de la Confederación Perú-Boliviana, será Andrés de Santa Cruz el que triunfe sobre Salaverry.

La imagen de Salaverry recogida en «Al pie de la letra» corresponde al último tramo de su vida, marcado por el golpe de Estado que protagonizará en el castillo del Real Felipe en el Callao el 22 de febrero de 1835 hasta la batalla de Socabaya en Arequipa, por cuya derrota fue fusilado el 18 de febrero de 1836 por órdenes del general triunfante, Andrés de Santa Cruz.

En esta corta etapa de casi un año, Salaverry, a su poder castrense, adicionó el poder político al haberse autoproclamado Jefe Supremo y, como tal, haber asumido de facto las funciones de Presidente de la República.

Al interés y la simpatía que había despertado Salaverry por haber subsumido el poder militar y el poder político en su personalidad y su conducta, se agrega el de la juventud, pues 
se veía como una carrera meteórica, signada por el espíritu de arrojo, audacia y hasta temeridad que le permitieron llegar al alto grado de general de brigada a los 28 años de edad, ser presidente de la república y morir fusilado a los 29 años de edad, enarbolando las banderas políticas del nacionalismo y de la moralidad en la función pública.

Palma en otra tradición, «La Salaverrina», enfatiza el prestigio popular y la simpatía ciudadana que estimuló su golpe militar y sus funciones presidenciales. Así escribió:

El 23 de febrero de 1835, un joven de 28 años de edad, pues nació en Lima el 2 de mayo de 1806, y que recientemente había obtenido el ascenso a general de brigada, alzaba en la fortaleza del Callao la bandera de la revolución contra el gobierno del presidente constitucional don Luis José Orbegoso. Al día siguiente, el pueblo de Lima armonizó con la causa y principios proclamados por el flamante Jefe Supremo (1953, p. 1079).

A renglón seguido continuará censurando el desatino político de Orbegoso que lo llevó al desprestigio para exaltar el buen recibimiento cívico del levantamiento, al que alude en los siguientes términos: «... y la del revolucionario general Salaverry ganó prestigio, pues toda la juventud se agrupó en torno del pabellón de la patria, simbolizado en el joven caudillo. El país se hizo salaverrino» (ibíd.).

Esta simpatía colectiva se acrecienta con la simpatía personal en Palma, porque ve en esa personalidad vetas de inspiración literaria. 


\subsection{La acciones}

Desde el punto de vista literario, las acciones son tres:

a) La demolición efectuada por el capitán Paiva de la casa del ciudadano, a quien Salaverry había mandado verbalmente apresar;

b) el fusilamiento por el capitán Paiva de Cuculí, el soldado asistente del general, malentendiendo la orden verbal que le imparte Salaverry; y

c) la muerte del capitán Paiva como consecuencia de una iniciativa personal de atacar un ejército enemigo, malinterpretando una expresión coloquial del general Salaverry que no constituía una orden.

\subsection{El mensaje}

«Al pie de la letra» es el título del texto. En su relación con su fondo o contenido ya resulta irónico respecto a la imagen profesional del militar, al que lo presenta en la figura del capitán Paiva como hombre inculto, de poca inteligencia, de mucha fuerza física, de obrar rápido e irreflexivo, junto a poco sentimental.

Respecto al general Felipe Santiago Salaverry, el lector infiere la imagen del militar que maneja el poder castrense propio de su rango al que ha añadido el poder político de la presidencia del país, para dictar medidas sin sujeción a los reglamentos militares ni a las leyes ni a la Constitución. 


\section{Análisis jurídico del texto}

\section{La Constitución de 1834}

Habiendo ocurrido los hechos materia de la tradición «Al pie de la letra» en 1835, en ese año se encontraba vigente la Constitución de 1834, aprobada por la Convención Nacional y promulgada por el presidente de la República general Luis José Orbegoso el 10 de junio de dicho año. Rigió hasta el 10 de noviembre de 1839 en que pone en vigencia la Constitución de 1839 el presidente Agustín Gamarra.

La Constitución de 1834 fue dictada por disposición de la propia Constitución de 1828, siendo, como advierte Basadre en su monumental Historia de la República del Perú 1822-1933, «La cuarta que se redactaba en el Perú en once años y la tercera de tipo liberal» (p. 283, t. 2).

Reconocida su vinculación sustantiva entre ambas constituciones, la de 1834, según José Pareja Paz Soldán (1984), «reproduce, casi literalmente, la Constitución de 1828. Las diferencias que hay son de detalle y los artículos modificados, como hemos dicho, no llegaron a veinte» (p. 62). En referencia al tratamiento constitucional que le dispensa al Poder Ejecutivo, una de sus características es «una inclinación marcada para establecer, en vista de inmediata experiencia del gobierno de Gamarra, nuevas restricciones a los poderes del Presidente de la República» ( p. 63).

A su perfil normativo de ser una suerte de reproducción de la Constitución de 1828 , se añade su vigencia teórica y su debilidad jurídica, pues nadie la respeta, al punto que el acceso mismo a la Presidencia de la República del general Felipe Santiago Salaverry, personaje literario de la tradición, fue debido al golpe 
militar que encabezó el 22 de febrero de 1835 en el castillo del Real Felipe del Callao. Algo de esto ha captado Manuel Vicente Villarán (1998) en sus Lecciones de Derecho Constitucional, quien sobre este particular sostiene:

La Constitución del 34 tuvo la mala fortuna de imperar en un período en que el país se hallaba conmovido por las guerras civiles. Prácticamente, estuvo en suspenso por este estado de trastorno en el país durante el período de 1834 a 1839. En este período tuvo lugar el famoso ensayo de la Confederación Perú-boliviana intentado por el general Santa Cruz (pp. 537-538).

A pesar de su inaplicación en la realidad y su inobservancia por los gobernantes, los derechos aparecían en su formulación claros y categóricos. Véase, entonces, los relacionados a los hechos registrados por la pluma de Palma en «Al pie de la letra».

\subsection{Garantías constitucionales sobre la libertad personal}

Art. $151^{\circ}$ Ninguno puede ser arrestado ni preso sin precedente información del hecho por el que merezca pena corporal, y sin mandamiento por escrito de juez competente, que se le intimará al tiempo de la aprensión (2017, p. 319).

Art. $152^{\circ}$ Para que alguno pueda ser arrestado sin las condiciones del artículo anterior, deberá serlo o en el caso del artículo $86^{\circ}$ restricción $5^{\mathrm{a}}$. o en el de delito infraganti, y entonces podrá arrestarlo cualquiera persona que deberá conducirlo inmediatamente a su respectivo juez (2017, p. 320). 
Art. $86^{\circ} \quad$ Son restricciones del Poder Ejecutivo:

5a. No puede privar de la libertad personal, y en caso de que así la seguridad pública, podrá librar orden de arresto, debiendo poner dentro de cuarenta y ocho horas al detenido a disposición del juez respectivo (2017, p. 307).

\subsection{Garantías constitucionales sobre la inviolabilidad del domicilio}

Art. $155^{\circ}$ La casa de todo peruano es un asilo inviolable: su entrada solo se franqueará en los casos y de la manera que determine la ley. (2017, p. 320)

\subsection{Garantías constitucionales sobre la inviolabilidad de la propiedad}

Art. 161 ${ }^{\circ}$ Es inviolable el derecho de propiedad. Si el bien público legalmente reconocido exigiere que se tome la propiedad de algún ciudadano, será previamente indemnizado de su valor (ibíd.).

La suerte de la Constitución de 1834 no es única ni exclusiva. La corta vigencia e inaplicabilidad en la realidad fue un mal crónico en el país. La Constitución de 1823, que organizaba la República, fue sustituida por la de 1826 y esta por la de 1828 . A ella le sucede la de 1834, que rigió nominalmente hasta 1839.

El drama político-jurídico del irrespeto y desacato a la Constitución viene acompañando al pueblo peruano durante todos los tiempos republicanos. 
En el caso de Salaverry y la tradición «Al pie de la letra», se tiene un ejemplo irrefutable. Por un lado, la Constitución de 1834 al momento de su sublevación en el Real Felipe del Callao no tenía ni un año de vigencia; $y$, por otro, mediante el artículo $173^{\circ}$ proscribía y sancionaba los golpes de Estado que facilitaban el acceso al «mando supremo de la República» por ser otro medio distinto al constitucional. La figura era calificada como usurpación del poder político y la sanción recaía en la persona, a quien se le condenaba a la pérdida sin rehabilitación de sus derechos políticos; y, sobre sus actos, los que eran declarados nulos, debiendo volver las cosas «al estado en que se hallaban antes de la usurpación, luego que se restablezca el orden» (2017, p. 322). Por supuesto que a Salaverry no le privaron de sus derechos políticos ni declararon la nulidad de sus actos de gobierno.

\section{Los hechos jurídicos}

De acuerdo a la teoría, el hecho jurídico se diferencia del acto jurídico por la presencia en el segundo de los designados de la voluntad; es decir, que los actos jurídicos responden a conductas intencionales y voluntarias y los hechos jurídicos son actos de la conducta humana desprovistos de voluntad, pero que sí tienen consecuencias que crean, modifican o extinguen derechos.

En este entendido, son tres los hechos jurídicos, correspondientes a cada historia que, en orden a su ocurrencia, se pasará a examinar:

\subsection{La detención de la persona y allanamiento de su domicilio}

Los hechos:

El general y presidente de la República Salaverry llama al capitán Paiva y le ordena verbalmente: 
a) Detener a un ciudadano en un lugar que no es su domicilio;

b) allanar su casa en el caso de que no fuera ubicado en el sitio primeramente indicado.

Se trata de una orden violatoria del derecho constitucional del ciudadano aludido previsto en el artículo $151^{\circ}, 152^{\circ}$ y en la restricción $5^{\mathrm{a}}$ del artículo $86^{\circ}$ de la Constitución de 1834 , que requieren proceso previo y mandamiento escrito de juez o apresar para poner a disposición del juez dentro de 48 horas.

También trasgrede el derecho constitucional de inviolabilidad del domicilio reconocido por el artículo $155^{\circ}$ de la Constitución de 1834 .

Desde la conducta del capitán Paiva, que es el ejecutor de la orden, interpretando erróneamente la palabra allanar, demuele la casa del ciudadano perseguido, afectándole en su derecho a la inviolabilidad de la propiedad, protegido por el artículo $161^{\circ}$ de la Constitución Política de 1834.

Vista la orden como tal demuestra que no fue intención del emisor, el general Salaverry, afectar el derecho de propiedad del ciudadano; este resultado ocurrió debido a la actuación del capitán Paiva, explicada por su interpretación negligente de la orden recibida.

\subsection{Fusilamiento del soldado Cuculí, asistente del general Salaverry}

Nuevamente el general y presidente del Perú, Salaverry, llama al capitán Paiva y le da la orden: «Llévate ahora mismo a este bribón al cuartel de granaderos y fusílalo entre dos luces» (1953, p. 1070). 
Estudiando la orden cabe ver:

a) Sujeto emisor: general Salaverry

b) Tipo de orden: verbal, fuera de proceso

c) Carácter de la orden: instancia única, porque no viene recomendada de otro órgano o de otra jerarquía

d) Propósito de la orden: solo asustar al infractor

e) Naturaleza de la orden: Administrativa y específicamente disciplinaria. Debió emanar de juez militar competente, previo proceso.

f) Caracterización de la orden: Esta es una orden aparente, contraponiendo el concepto de orden verdadera. Se le denomina aparente porque el propósito de la orden no es fusilar de verdad al soldado Cuculí, sino intimidarlo con fines disciplinarios. También es expresión de ligereza, de desproporción, abuso de poder. Es un medio excesivo que emplea el general Salaverry para corregir la conducta díscola de su asistente.

La evidencia está en que el aparente fusilamiento se llevaría a cabo en la madrugada, dicho figurativamente «entre dos luces»; tiempo que le permitiría al general dar la contraorden de suspensión del fusilamiento, bajo apariencia de indulto.

Desde la posición del capitán Paiva esta misma orden ostenta otras características:

- El capitán Paiva no tiene la mínima duda de la certeza de la orden, entendiendo él que es ineludible su deber de cumplirla. 
- Paiva no tiene una conducta discrecional frente a la orden recibida.

- Paiva actúa con el criterio de subordinación y obediencia ciega al superior.

- El capitán Paiva lleva a cabo la ejecución de la orden tal cual su real saber y entender y obtiene un resultado distinto al de la intención de la orden; es decir, fusilando de verdad a Cuculí, el soldado asistente del general Salaverry.

\section{3. «Déjame en paz. Haz lo que quieras. Anda y hazte matar»}

Ahora la escena y el escenario narrativo cambian radicalmente. Ya no es el ambiente administrativo, sino un campo de batalla. Esta vez no es llamado el capitán Paiva para impartirle una orden. Los sucesos precisan que es el capitán Paiva quien busca al general Salaverry para pedirle que lo autorice a atacar al ejército enemigo, acompañado de un pequeño pelotón de soldados que él mismo escogería. Como Salaverry estaba convencido de lo innecesario del ataque no le dio ninguna orden formal, hasta que, ante tanta insistencia le dijo: «Déjame en paz. Haz lo que quieras. Anda y hazte matar» (p. 1070).

Analizándola, esta expresión no es formalmente una orden y menos una orden aparente. No obstante ello, el capitán Paiva siempre seleccionó a los soldados e hizo el ataque por su propia cuenta y responsabilidad.

Aquí se entra a una variante narrativa en cuanto a la actuación de los personajes. Al no haber dado ninguna orden formal Salaverry y haber llevado a cabo el ataque no autorizado, el 
capitán Paiva habría incurrido en un acto de insubordinación y desobediencia al superior, por el que no podía responder por haber ocasionado su propia muerte.

Cambiando el enfoque, esta acción sería para los militares expresión de valentía y patriotismo porque el ataque que encabezó el capitán Paiva fue contra un grupo del ejército boliviano que había ingresado a Arequipa en los momentos iniciales de la Confederación Peruano-Boliviana.

La muerte del capitán Paiva, por más que sea el resultado de su propia acción de insubordinación y desobediencia no se podría tomar como un suicidio, porque fue muerto en batalla entre dos ejércitos enemigos. Constitucionalmente, el capitán Paiva habría actuado dentro del gran marco establecido por el artículo $140^{\circ}$ que preceptúa: «El objeto de la fuerza pública es defender al Estado contra los enemigos exteriores, asegurar el orden interior y sostener la ejecución de las leyes» (2017, p. 318), quedando la figura legal solo a ser calificada por la legislación militar. De acuerdo a esta, podría imputársele la conducta de haber incumplido su deber de obediencia, interpretando que ante la negativa expresa de autorizarlo, se habría configurado una orden tácita de no atacar.

La otra posibilidad interpretativa de los hechos conduciría a aceptar que la expresión «Déjame en paz. Haz lo que quieras. Anda y hazte matar» constituyó, en la mentalidad del capitán Paiva, una orden verbal informal del ataque al ejército enemigo en la fórmula planteada.

En la hipótesis que a esta expresión del estado de ánimo de fastidio del general Salaverry por tanta insistencia, se le diera el valor de una orden verbal informal y tácita de ataque, el capitán Paiva no habría incurrido en acto de insubordinación ni desobediencia al superior. 
Ante esta posibilidad interpretativa, la acción de ataque del capitán Paiva sería militarmente calificada como heroica, aunque solo hubiera sido una incursión no una batalla.

\section{Conclusiones}

5.1. «Al pie de la letra» es una tradición conformada por tres historias referidas a acciones distintas comparándolas entre sí, pero que alcanzan unidad textual gracias a que en las tres historias actúan como protagonistas los dos personajes centrales: el general Salaverry y el capitán Paiva y se desarrolla el tema del modo de ser militar sujeto a disciplina y obediencia.

5.2. Que siendo «Al pie de la letra» un texto literario, esto es, una obra de arte, en cada historia aparecen como componentes hechos jurídicos que le dan valor de fuente del Derecho $\mathrm{y}$, consecuentemente, de objeto de estudio por la ciencia jurídica.

5.3. Los hechos jurídicos presentados pueden ser estudiados desde el punto de vista del Derecho civil, Derecho penal, Derecho constitucional o de la legislación militar.

En el presente ensayo el estudio se ha circunscrito al Derecho constitucional sin agotar cada punto, por estar dirigido a los estudiantes que están iniciándose en la formación profesional del abogado.

5.4. Tal como es presentada la actuación de los personajes, informa la existencia en la sociedad peruana de 1835 de una mentalidad familiarizada con estos hechos, consecuentemente tolerante con todos ellos: golpe de Estado, abuso de poder, carencia de derechos, irrespeto e inaplicación de la Constitución e impunidad. 


\section{Referencias bibliográficas}

Basadre, J. (s/f). Historia de la República del Perú 1822-1933. Lima: diario La República y la Universidad Ricardo Palma.

Las Constituciones del Perú. (2017). Biblioteca Jurídica del Bicentenario, Tribunal Constitucional y Ministerio de Justicia y Derechos Humanos. Estudio Preliminar de Carlos Ramos Núñez. Lima.

Durand Flórez, L. (1998), La República 1826-1899, compendio histórico

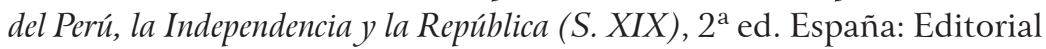
Milla Batres.

Palma, R. (1953). Tradiciones Peruanas Completas. 2a ed. Madrid: ediciones Aguilar.

Pareja Paz Soldán, J. (1984). Derecho Constitucional peruano y la Constitución de 1979. $3^{\mathrm{a}}$ edición. Lima: Ediciones Justo Valenzuela.

Villarán, M. V. (1998). Lecciones de Derecho Constitucional. Lima: Pontificia Universidad Católica del Perú.

Zanutelli Rosas, M. (1994). Salaverry, Felipe Santiago. En Enciclopedia Biográfica Histórica del Perú, siglos XIX-XX, Colombia: Editorial Milla Batres. 